\title{
Calculating physician supply using a service day method and the income percentiles method: a descriptive analysis
}

\author{
Terrence McDonald MD MSc, Brendan Cord Lethebe MSc, Lee A. Green MD MPH
}

Abstract

Background: It is important to have an accurate count of physicians and a measurable understanding of their service provision for physician resource planning. Our objective was to compare 2 methods (income percentiles [IP] and service day activities [SVD]) for calculating the supply of full-time (FT) and part-time (PT) primary care physicians (PCPs) as measures of both physician supply counts and level of provider continuity.

Methods: Using an observational study design, we compared 2 methods of calculating the supply of PT and FT PCPs for 2011-2015. For the IP approach, the Canadian Institute for Health Information's method was applied to Alberta Health billing data. The SVD method calculated annual service days for fee-for-service PCPs. A simple descriptive analysis was conducted of the supply of PT and FT PCPs.

Results: The 2 methods agreed on the FT versus PT status of $85.2 \%$ of PCPs in 2015 but disagreed on the status of 490 PCPs. A total of 239 PCPs were classified as working FT by the IP method but PT by the SVD method. Two hundred and fifty-one PCPs were classified as working PT according by the IP method but FT by the SVD method. The former group of 239 PCPs worked fewer days per week (3.22 v. 4.1) and fewer weekend days per year (8.6 v. 24.1), billed more per year ( $\$ 300327$ v. $\$ 201834$ ) and saw more patients per day (26.8 v. 17.8) with less continuity of care (38.0\% v. $72.0 \%)$ than the latter group of $251 \mathrm{PCPs}$.

Interpretation: The SVD method provides a valid alternative to calculating GP supply that distinguishes groups of physicians that the standard IP methodology does not. Those groups provide very different service; policy-makers may benefit from distinguishing them.

F stimating primary care physician (PCP) resources in Canadian provinces, in terms of both the numbers of physicians and their patterns of practice, is important for health resource planning. Accurate estimates are needed to guide policies that support patient access and continuity of care, as both have been shown to improve health outcomes. ${ }^{1-5}$ Across Canada, health resource planning relies largely on head counts and full-time equivalent (FTE) estimates of PCPs using information and methods from the Canadian Institute for Health Information (CIHI). ${ }^{6-11}$ The income percentile (IP) method used by CIHI estimates the number of FTEs on the basis of income thresholds that are based on gross physician income, which is calculated from fee-for-service payments. Primary care physicians with incomes below, within or above the 40th to 60th percentile interval are categorized as being less than, equal to or more than 1.0 FTE, respectively. ${ }^{8}$ These FTE counts are then used to calculate national and provincial physician-topopulation ratios or to serve as simple head counts.

The IP method can classify high-billing part-time (PT) physicians as working full-time (FT) and low-billing FT physicians as working PT. This is important to understand for health policy-makers who rely on estimates calculated with the IP method to evaluate current service supply. In discussions in the public sphere, physician-to-population ratios calculated using PCP FTEs are often used as a measure of access to health care. ${ }^{12}$ However, because the IP method could count a physician who provides a high volume of short visits on a minority of days a week as working FT, it may not provide an accurate picture of patient service or access. ${ }^{13-15}$

As an alternative to the IP method, we propose a novel method using service days (the service day activities [SVD] method), to calculate the number of PCPs in FT and PT

Competing interests: None declared.

This article has been peer reviewed.

Correspondence to: Terrence McDonald, Terrence.McDonald@ucalgary.ca

CMAJ Open 2020. DOI:10.9778/cmajo.20200037 
practice. We developed the SVD method in a previous study to identify and describe PCPs with high-volume practices in Alberta. ${ }^{16}$ In that work we discovered that some physicians were in clinic on relatively few days but generated very high billings, leading us to hypothesize that the IP method may not yield an accurate picture of FT and PT PCPs. Further, because continuity of care has long been known to be important in improving outcomes, the presence of high-billing physicians who appear to be working FT by the IP method but who are in clinic less often than other FT physicians will have different implications for physician service planning than if all FT physicians had similar practice patterns. ${ }^{17}$

We propose that the additional perspective of the SVD method will offer added value to health workforce planners. Our objectives in this study were to compare the IP method and SVD methods as measures of both physician supply and continuity.

\section{Methods}

\section{Study design}

A descriptive analysis was conducted on data for all PCPs whose payment model was fee-for-service (FFS) in Alberta, Canada, to compare the IP and SVD methods of describing physician supply using an observational cohort.

\section{Study cohort and setting}

All FFS PCPs in Alberta practising between April 2011 and March 2016 were included in this study. The study cohort comprised over $80 \%$ of PCPs practising in Alberta, and their sole payment model was FFS. Alberta does not have the widespread participation in alternative payment models that other provinces do, making it well suited for the present analysis. The physicians who work in alternative payment models are mostly either in academic positions or serve specific populations such as frail older people or patient with complex social needs. The practices of these physicians are atypical and their FTE value is precisely defined and known; hence, they are not informative for this analysis.

\section{Data sources}

Provincial physician claims data were obtained from Alberta Health for all study physicians for the period Apr. 1, 2011, to Mar. 30, 2016. Each PCP's main service delivery site was identified from billing data, which include a physical address where service is delivered. This information is anonymized in our data set, but we had access to sufficient detail to determine the geographic area where each physician practised (see below). This data set has been shown to have value and face validity for health services research. ${ }^{18} \mathrm{~A}$ second data set containing information on the study physicians' demographic characteristics, including provider sex, years since medical school graduation and country of medical school training, was obtained from the College of Physicians and Surgeons of Alberta. This data set is a complete registry of all physicians in Alberta and was merged with the physician claims data.

\section{Calculations by the SVD method}

The mean daily volume of patient visits was calculated as the mean number of visits per service day. Total service days for each PCP for the entire fiscal year in 2015 were used. A physician was determined to have worked 1 service day if they billed 10 or more patient visits on 1 calendar day. To be included in this calculation, a patient visit had to have been associated with a fee of at least $\$ 25$. This fee threshold captured almost all PCP visit codes from the schedule of medical benefits of the Alberta Health Care Insurance Plan, including office visits as well as hospital and long-term care visits. ${ }^{19,20}$ Fees below $\$ 25$ did not represent visits (with 1 exception) but rather were ancillary charges to visits (e.g., for Papanicolaou smears); hence, the $\$ 25$ threshold cleanly separates visits from other charges. The common fee code exception that was under $\$ 25$ was for phone calls.

We selected the threshold of 10 patient visits per day because inspection of the data revealed a qualitative difference above and below this threshold: physicians who had substantial numbers of days on which they worked but saw fewer than 10 patients were very few in number and had atypical practices, mostly focused on psychotherapy or surgery. This threshold did not separate half days from full days, but as billing data are not time stamped and physicians work at different paces, there is no simple threshold that can achieve this separation.

In cases where the same code over $\$ 25$ was billed multiple times by a single provider for a single patient on a single day, we coded 1 visit (such instances accounted for only $0.08 \%$ of all billings). In cases in which several different codes were billed by a single provider for a single patient on a single day, we coded each of the codes as separate visits. This occurred with only $0.4 \%-0.9 \%$ of all claims between 2011 and 2015 . Inspection showed that multiple visits for a single patient on the same day with the same provider are typically a combination of office-based surgeries, visits to the hospital or visits to a long-term care facility, representing genuine additional service rather than redundant data.

In the SVD method, physicians are defined as working FT if they provide 3 or more service days per week over 46 weeks of the year. Physicians are defined as working PT if they provide fewer than 3 service days per week over 46 weeks of the year. We chose 46 weeks for these definitions as that is the number of weeks that Alberta family physicians typically work in a work year and we chose 3 service days per week on the basis of our previous work on physician practice volumes. ${ }^{16}$

\section{Calculations by the IP method}

The IP method used by CIHI classifies physicians as working FT versus PT by calculating the total amount paid to each primary care physician. The 40th and 60th percentiles of the total amount paid by FFS claims are calculated for all physicians. Physicians for whom the amount paid falls between the 40th and 60th percentiles are considered 1.0 FTE. The FTE for physicians whose income is below the 40th percentile is calculated as total payments divided by the lower benchmark. For physicians whose income is above the 60th percentile, it is calculated as 1 plus $\ln ($ total payments 
divided by upper benchmark). CIHI defines physicians under 1.0 as working PT and those greater than or equal to 1.0 as working FT. ${ }^{8}$

\section{Determination of patient provider continuity and panel size}

Patient continuity was determined by the percentage of each patient's claims attributed to their primary provider. Primary provider patient panels were determined by the commonly used 4-cut method as described by Murray and colleagues and the Health Quality Council of Alberta. ${ }^{21,22}$ The Health Quality Council of Alberta is a provincial agency focused on health quality and safety, and it uses the 4-cut method to attribute patient panels for the purpose of providing patient panel reports to primary care physicians. ${ }^{22}$

\section{Alberta geographic zones and rural-urban continuum}

The province of Alberta is divided by Alberta Health Services into 5 geographic zones for health administration and into 7 population density ranges along the rural-urban continuum, from high (metro centres) to low (rural remote), for planning and analytic purposes..$^{23,24}$ Both geographic zone and position on the rural-urban continuum were considered in this analysis.

\section{Statistical analysis}

The unit of analysis was the physician. To describe physician patterns of care (physician service days, patient volume, physician income, continuity, panel size), categorical variables were summarized using proportions and counts, while numeric variables were reported with means and standard deviations. Descriptive statistics were summarized for FT versus PT physician supply categories.

We estimated the above descriptives for both the IP method and SVD method. We calculated $\kappa$ to demonstrate the level of agreement between the SVD method and the IP method.

A sensitivity analysis was conducted to determine consistency of physician supply over time. The above analysis was rerun for fiscal years 2011 to 2015. Analyses were conducted using R statistical software version 3.3.2.

\section{Ethics approval}

Ethics approval was obtained from the Conjoint Health Research Ethics Board of the University of Calgary (study identification no. REB17-1301).

\section{Results}

\section{Assessment of physician supply by the SVD method}

This analysis was conducted each year from 2011 to 2015. Here we report results for 2015; results for the remaining years can be found in Appendix 1 (Supplemental Tables S1S4, available at www.cmajopen.ca/content/8/4/E747/suppl/ DC1). In 2015, there were 2151 physicians classified as working FT and 1170 physicians classified as working PT by the SVD method.
Part-time PCPs worked a mean of 1.7 days per week whereas FT PCPs worked a mean of 4.4 days per week. (Table 1). The mean number of weekend service days in 2015 provided by PT physicians was 12.0 days, compared with 21.2 days by FT physicians (Table 1). Considering all days on which at least 1 patient was seen, PT physicians averaged 2.5 days per week and FT physicians averaged 4.8 days per week (Table 1).

The median annual billing was $\$ 376846$ for FT physicians and \$147 265 for PT physicians (Table 1). The mean panel size was 1199.8 patients for FT physicians and 343.2 for PT physicians. The mean volume of patients seen per day was 27.9 for FT physicians and 18.8 for PT physicians (Table 1 ).

The proportion of $\mathrm{PT}$ providers was greatest in zones 2 and 4, which contain Calgary and Edmonton, respectively (Table 1). The same urban-centric pattern of PT practice was seen on the urban-rural continuum.

\section{Comparison of the SVD method and the IP method}

The SVD and IP methods estimated similar numbers of FT and PT physicians overall but showed substantial differences in detail, and in continuity. In terms of classifying physician supply into FT and PT, the SVD and IP methods agreed on $85.2 \%$ of physicians in 2015 (Table 2); the 2 methods disagreed for 490 physicians. Specifically, the IP method estimated that 239 physicians worked FT who, according to the SVD, only worked PT (subsequently called the PT ${ }^{S}$ FT $^{I}$ cohort). Similarly, 251 physicians were considered to work PT, according to the IP method, but were considered to work FT by the SVD method (subsequently called the FTSPT ${ }^{\mathrm{I}}$ cohort). The $\kappa$ (agreement) between the SVD and IP methods was 0.677 (95\% confidence interval 0.651-0.704) (Table 3).

There substantial differences between the patterns of care for the $\mathrm{PT}^{\mathrm{S}} \mathrm{FT}^{\mathrm{I}}$ and the $\mathrm{FT}^{\mathrm{S}} \mathrm{PT}^{\mathrm{I}}$ cohorts. The PT ${ }^{\mathrm{S}} \mathrm{TT}^{\mathrm{I}}$ cohort worked fewer days per week $(3.2$ v. $4.1 \mathrm{~d})$ and fewer weekend days per year $(24.1$ v. $8.6 \mathrm{~d})$, saw at least 1 patient on fewer days per year (148.2 v. $189.0 \mathrm{~d})$, billed more per year (\$300 327 v. \$201 834), saw more patients per day (26.8 v. 17.8 patients), had smaller panel sizes (527.3 v. 760.1 panels) and had less continuity of care $(38.0 \%$ v. $72.0 \%)$ than the $\mathrm{FT}^{\mathrm{S}} \mathrm{PT}^{\mathrm{I}}$ cohort (Table 2).

\section{Sensitivity analysis}

Results across study years (2011 to 2015) are presented in Appendix 1 (Supplemental Tables S1-S4). A consistent number of PCPs who were classified as working FT by the IP method were classified as working PT by the SVD method. Similarly, a consistent number of PCPs who were classified as working FT by the SVD method were classified as working PT by the IP method. The overall proportion of PT PCPs increased over the study period. The range of the $\kappa$ was consistent over the years 2011 to 2015 (range 0.65-0.67) (Table 3).

Descriptive statistics were calculated for each fiscal year, with no material differences between years. We varied the definition of a service day for a provider from our base case of 

Table 1: Characteristics of primary care physicians and their practices in Alberta in 2015, categorized by practice
status (part-time or full-time) determined by the service day activities method

\begin{tabular}{|c|c|c|}
\hline Characteristic & $\begin{array}{c}\text { Part-time } \\
n=1170\end{array}$ & $\begin{array}{l}\text { Full-time } \\
n=2151\end{array}$ \\
\hline \multicolumn{3}{|l|}{ Physician characteristics } \\
\hline Sex, male, no. (\%) & $512(43.8)$ & $1452(67.5)$ \\
\hline No. of years since graduation, mean \pm SD & $20.4 \pm 13.4$ & $22.6 \pm 11.7$ \\
\hline International medical graduate, no. (\%) & $200(17.1)$ & $794(37.0)$ \\
\hline \multicolumn{3}{|l|}{ Service days } \\
\hline No. of service days with $\geq 10$ patients, mean \pm SD & $78.4 \pm 40.8$ & $201.9 \pm 39.0$ \\
\hline No. of service days with $\geq 20$ patients, mean \pm SD & $41.5 \pm 36.9$ & $154.8 \pm 63.5$ \\
\hline No. of service days with $\geq 1$ patient, mean $\pm S D$ & $115.6 \pm 55.6$ & $223.3 \pm 41.2$ \\
\hline No. of service days per week with $\geq 10$ patients, mean & 1.7 & 4.4 \\
\hline No. of service days per week with $\geq 1$ patient, mean & 2.5 & 4.8 \\
\hline No. of service days with $<10$ patients, mean \pm SD & $37.2 \pm 46.1$ & $21.4 \pm 23.0$ \\
\hline No. of weekend service days with $\geq 10$ patients, mean \pm SD & $12.0 \pm 13.3$ & $21.2 \pm 20.1$ \\
\hline No. of weekend service days with $\geq 20$ patients, mean \pm SD & $9.3 \pm 12.3$ & $16.5 \pm 18.7$ \\
\hline Gross annual revenue, $\$$, median (IQR) & $147265(86611-212450)$ & $376846(284797-502$ 128) \\
\hline \multicolumn{3}{|l|}{ Panel characteristics and patient volume } \\
\hline Panel size, no. of patients, mean \pm SD & $343.2 \pm 263.7$ & $1199.8 \pm 658.1$ \\
\hline Percentage of claims from panel, ${ }^{*}$ mean \pm SD & $45.2 \pm 24.6$ & $69.4 \pm 21.3$ \\
\hline Average patient volume, $\uparrow$ mean \pm SD & $18.8 \pm 10.5$ & $27.9 \pm 11.4$ \\
\hline \multicolumn{3}{|l|}{ Practice location by zone, $\ddagger$ no. (\%) } \\
\hline Zone 1 & $67(5.7)$ & $171(7.9)$ \\
\hline Zone 2 & $495(42.3)$ & 785 (36.5) \\
\hline Zone 3 & $106(9.1)$ & $270(12.6)$ \\
\hline Zone 4 & $365(31.2)$ & 727 (33.8) \\
\hline Zone 5 & $98(8.4)$ & $190(8.8)$ \\
\hline Unknown zone & 39 (3.3) & $8(0.4)$ \\
\hline \multicolumn{3}{|l|}{ Practice location by urban-rural continuum,‡ no. (\%) } \\
\hline Urban & $101(8.6)$ & $242(11.3)$ \\
\hline Metro & $704(60.2)$ & $1127(52.4)$ \\
\hline Moderate metro influence & $99(8.5)$ & $301(14.0)$ \\
\hline Moderate urban influence & $6(0.5)$ & $24(1.1)$ \\
\hline Rural & $165(14.1)$ & $317(14.7)$ \\
\hline Rural centre area & $36(3.1)$ & $91(4.2)$ \\
\hline Rural remote & $20(1.7)$ & $41(1.9)$ \\
\hline Unknown & $39(3.3)$ & $8(0.4)$ \\
\hline \multicolumn{3}{|c|}{$\begin{array}{l}\text { Note: IQR = interquartile range, } S D=\text { standard deviation. } \\
\text { *Proportion of claims for the patients in a primary care physician's panel that are attributed to that physician. } \\
\text { †Average number of patients seen per day. } \\
\text { fGeographic zones and population density ranges along the urban-rural continuum defined by Alberta Health Services. }{ }^{23,24}\end{array}$} \\
\hline
\end{tabular}

10 services billed at at least $\$ 25$ for 1 or more, 5 or more, and 20 or more patients. When we used these different cut-points, the counts changed in the categories, but the overall pattern remained unchanged. Supplemental Table S5 in Appendix 1 presents descriptive information on PT physicians working fewer than 30 days per year who were included in the analysis to illustrate the very PT outliers.

\section{Interpretation}

It is important to have an accurate count of physicians and a measurable understanding of their service provision for physician resource planning. ${ }^{25,26}$ In our analysis, the IP method and the SVD method yielded somewhat different pictures. It is important that policy-makers understand 
Table 2: Characteristics of primary care physicians and their practices in Alberta in 2015, categorized by whether the service day activities method and the income percentiles method agreed on the determination of practice status (part-time or full-time)

\begin{tabular}{|c|c|c|c|c|}
\hline Characteristic & $\begin{array}{l}\text { PTAGREE } \\
n=931\end{array}$ & $\begin{array}{l}\mathrm{PT}^{\mathrm{S}} \mathrm{FT}^{\mathrm{I}} \\
n=239\end{array}$ & $\begin{array}{l}\mathrm{FT}^{\mathrm{SP}} \mathrm{PT}^{1} \\
n=251\end{array}$ & $\begin{array}{c}\text { FT }^{\text {AGREE }} \\
n=1900\end{array}$ \\
\hline \multicolumn{5}{|l|}{ Physician characteristics } \\
\hline Sex, male, no. (\%) & $355(38.1)$ & $157(65.7)$ & $108(43.0)$ & $1344(70.7)$ \\
\hline$\kappa^{*}$ & \multicolumn{4}{|c|}{$0.677(0.651-0.704)$} \\
\hline No. of years since graduation, mean \pm SD & $20.3(13.8)$ & $20.8(12.0)$ & & $22.5(11.5)$ \\
\hline International medical graduate, no. (\%) & $164(17.6)$ & $36(15.1)$ & $47(18.7)$ & 747 (39.4) \\
\hline \multicolumn{5}{|l|}{ Service days } \\
\hline No. of service days with $\geq 10$ patients, mean \pm SD & $70.0(39.9)$ & $110.8(25.3)$ & $166.6(22.6)$ & $206.5(38.0)$ \\
\hline No. of service days with $\geq 20$ patients, mean \pm SD & $30.9(29.5)$ & $82.8(33.6)$ & $67.99(42.1)$ & $166.3(56.7)$ \\
\hline No. of service days with $\geq 1$ patient, mean \pm SD & $107.2(56.3)$ & $148.2(38.0)$ & $189.0(28.8)$ & $227.8(40.5)$ \\
\hline $\begin{array}{l}\text { No. of service days per week with } \geq 10 \text { patients, } \\
\text { mean }\end{array}$ & 1.5 & 2.41 & 3.6 & 4.5 \\
\hline $\begin{array}{l}\text { No. of service days per week with } \geq 1 \text { patient, } \\
\text { mean }\end{array}$ & 2.3 & 3.22 & 4.1 & 5.0 \\
\hline No. of service days with $<10$ patients, mean \pm SD & $37.20(45.8)$ & $37.37(47.3)$ & $22.45(20.5)$ & $21.27(23.4)$ \\
\hline $\begin{array}{l}\text { No. of weekend service days with } \geq 10 \text { patients, } \\
\text { mean } \pm \text { SD }\end{array}$ & $8.08(10.2)$ & $24.07(14.5)$ & $8.63(12.6)$ & $22.42(20.2)$ \\
\hline $\begin{array}{l}\text { No. of weekend service days with } \geq 20 \text { patients, } \\
\text { mean } \pm \text { SD }\end{array}$ & $5.54(8.7)$ & $21.05(14.3)$ & $4.90(9.5)$ & $17.65(18.9)$ \\
\hline Gross annual gross revenue, $\$$, median (IQR) & $\begin{array}{c}122716 \\
(72135-165991) \\
\end{array}$ & $\begin{array}{c}300327 \\
(254836-348294)\end{array}$ & $\begin{array}{c}201834 \\
(180156-218511)\end{array}$ & $\begin{array}{c}400516 \\
(318280-524322)\end{array}$ \\
\hline \multicolumn{5}{|l|}{ Panel characteristics and patient volume } \\
\hline Panel size, no. of patients, mean \pm SD & $295.9(212.0)$ & $527.3(351.0)$ & $760.1(226.3)$ & $1257.8(674.3)$ \\
\hline $\begin{array}{l}\text { Percentage of claims from panel, } \dagger \\
\text { mean } \pm \text { SD }\end{array}$ & $47.1(24.8)$ & $38.0(22.4)$ & $72.0(19.8)$ & $69.1(21.5)$ \\
\hline Average patient volume, $\neq$ mean $\pm S D$ & $16.7(7.9)$ & $26.8(14.7)$ & $17.8(3.9)$ & $29.3(11.4)$ \\
\hline \multicolumn{5}{|l|}{ Practice location by zone,§ no. (\%) } \\
\hline Zone 1 & $56(6.0)$ & $11(4.6)$ & $13(5.2)$ & $158(8.3)$ \\
\hline Zone 2 & $408(43.8)$ & $87(36.4)$ & $105(41.8)$ & $680(35.8)$ \\
\hline Zone 3 & $83(8.9)$ & $23(9.6)$ & $14(5.6)$ & $256(13.5)$ \\
\hline Zone 4 & 278 (29.9) & $87(36.4)$ & $104(41.4)$ & $623(32.8)$ \\
\hline Zone 5 & $67(7.2)$ & $31(13.0)$ & $14(5.6)$ & $176(9.3)$ \\
\hline Unknown zone & $39(4.2)$ & $0(0)$ & $1(0.4)$ & $7(0.4)$ \\
\hline \multicolumn{5}{|l|}{ Practice location by urban-rural continuum,§ no. (\%) } \\
\hline Urban & $72(7.7)$ & $29(12.1)$ & $19(7.6)$ & $223(11.7)$ \\
\hline Metro & $572(61.4)$ & $132(55.2)$ & $163(64.9)$ & $964(50.7)$ \\
\hline Moderate metro influence & $72(7.7)$ & $27(11.3)$ & $39(15.5)$ & $262(13.8)$ \\
\hline Moderate urban influence & $4(0.4)$ & $2(0.8)$ & $3(1.2)$ & $21(1.1)$ \\
\hline Rural & $126(13.5)$ & $39(16.3)$ & $16(6.4)$ & $301(15.8)$ \\
\hline Rural centre area & $30(3.2)$ & $6(2.5)$ & $6(2.4)$ & $85(4.5)$ \\
\hline Rural remote & $16(1.7)$ & $4(1.7)$ & $4(1.6)$ & $37(1.9)$ \\
\hline Unknown & $39(4.2)$ & $0(0)$ & $1(0.4)$ & $7(0.4)$ \\
\hline \multicolumn{5}{|c|}{ 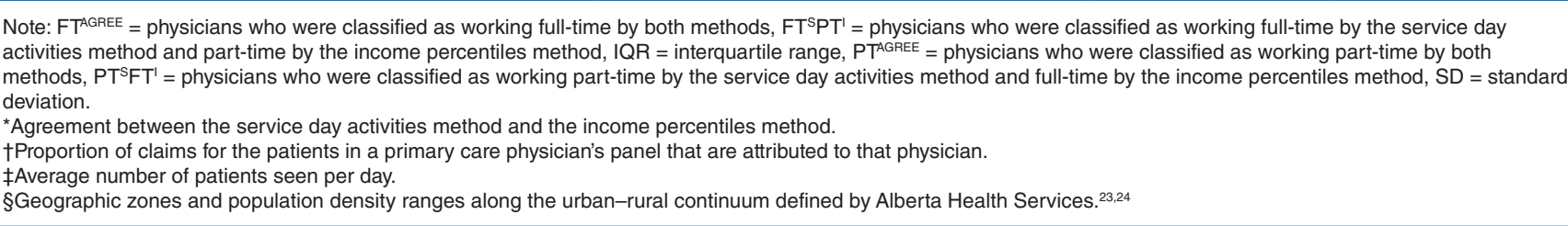 } \\
\hline
\end{tabular}




\begin{tabular}{|c|c|c|c|c|c|c|}
\hline \multirow[b]{2}{*}{ Year } & \multirow{2}{*}{$\begin{array}{l}\text { Total no. of } \\
\text { physicians }\end{array}$} & \multicolumn{4}{|c|}{ No. (\%) of physicians } & \multirow[b]{2}{*}{$\kappa(95 \% \mathrm{Cl})$} \\
\hline & & PTAGREE & $\mathrm{PT}^{\mathrm{S}} \mathrm{FT}^{\mathrm{I}}$ & $\mathrm{FT}^{\mathrm{S}} \mathrm{PT} \mathrm{T}^{\prime}$ & FTAGREE & \\
\hline 2015 & 3321 & $931(28.0)$ & $239(7.2)$ & $251(7.6)$ & $1900(57.2)$ & $0.68(0.65-0.70)$ \\
\hline 2014 & 3182 & $839(26.4)$ & $237(7.4)$ & $245(7.7)$ & $1861(58.5)$ & $0.66(0.64-0.69)$ \\
\hline 2013 & 3021 & $790(26.2)$ & $246(8.1)$ & $224(7.4)$ & $1761(58.3)$ & $0.65(0.62-0.68)$ \\
\hline 2012 & 2900 & $755(26.0)$ & $210(7.2)$ & $228(7.9)$ & $1707(58.9)$ & $0.66(0.63-0.69)$ \\
\hline 2011 & 2763 & $696(25.2)$ & $172(6.2)$ & 255 (9.2) & 1640 (59.4) & $0.65(0.62-0.68)$ \\
\hline \multicolumn{7}{|c|}{$\begin{array}{l}\text { Note: } \mathrm{Cl}=\text { confidence interval, } \mathrm{FT}^{\mathrm{AGREE}}=\text { physicians who were classified as working full-time by both methods, } \mathrm{FT}^{\mathrm{S}} \mathrm{PT} \mathrm{T}^{\mathrm{I}}=\text { physicians who were } \\
\text { classified as working full-time by the service day activities method and part-time by the income percentiles method, } \mathrm{PT}^{\mathrm{AGREE}}=\text { physicians who were } \\
\text { classified as working part-time by both methods, } \mathrm{PT}^{\mathrm{S}} \mathrm{FT} \text { 的 }=\text { physicians who were classified as working part-time by the service day activities method } \\
\text { and full-time by the income percentiles method. }\end{array}$} \\
\hline
\end{tabular}

the differences between the methods and their implications for planning.

The methods agreed on the classification of two-thirds of physicians. The remaining third of physicians can be classified into 2 cohorts. The first cohort consists of physicians who provide a high volume of services per day and have a high income but are in clinic few days per week (the $\mathrm{PT}^{\mathrm{S}} \mathrm{FT}^{\mathrm{I}}$ cohort). The second is made up of physicians who are calculated to work FT by service days but PT by income, that is, physicians who are in clinic often but do not bill large volumes (the $\mathrm{FT}^{\mathrm{S}} \mathrm{PT}^{\mathrm{I}}$ cohort).

These patterns have implications for workforce planning. Physicians who were calculated to work FT by income percentiles (i.e., billing volume) but $\mathrm{PT}$ by service days $\left(\mathrm{PT}^{\mathrm{S}} \mathrm{FT}^{\mathrm{I}}\right.$ ) may have been achieving that billing volume by providing a large number of short visits, using "1 problem per visit" rules. ${ }^{27}$ Such physicians had notably lower continuity of care in our data. Hence, although the volume of service for which they billed may have been large, the access they provided and the number of patients for whom they cared may not be consistent with their ostensible FT status. Conversely, although the physicians who were calculated to work PT by income percentiles but FT by service days $\left(\mathrm{FT}^{\mathrm{S}} \mathrm{PT}^{\mathrm{I}}\right)$ had the small panels expected of PT physicians, they were in clinic often and had high continuity of care. Therefore, they may have provided more service from the public's perspective than their income percentiles suggested.

The IP and SVD methods differed in terms of which physicians they identified as working FT and PT, but the 2 methods generated the same total numbers in each group. However, that is a happenstance of Alberta's current situation; planners should not count on that being the case and dismiss the SVD perspective. Further, although the FT and PT numbers were similar when averaged across the province, their local distributions were not. Particularly for planners examining physician supply in a single town or region, the IP and SVD methods may yield very different information.

The value of including the SVD method in assessments in Alberta and in other jurisdictions is that this method provides a more nuanced perspective on the adequacy of the local workforce in relation to population needs. In Ontario, for example, the results of a relative income-based method (such as CIHI's) to calculate physician workforce are difficult to interpret where different models of care are reimbursed at different levels for the same amount worked. The SVD method will help planners to identify underserviced areas more appropriately. When the 2 most popular payment models, family health groups (which are enhanced FFS) and family health organizations (which are blended capitation), are compared, physicians in family health organizations earn higher incomes for the same work, so an income-based approach distorts their relative FTEs. ${ }^{28}$ As such, service days are a much better reflection of FT or PT status than an FTE measure based on relative income.

These patterns' impact on timeliness of access and continuity of care should be considered by health workforce planners. Together with the effect of the general trend toward PT practice on patient access and continuity of care, ${ }^{29,30}$ they will affect estimates of desired physician supply in Canada.

\section{Limitations}

The primary limitation of this study was the absence of a time stamp on PCP claims. Hence, we could not estimate the number of work hours per week. As a result, we excluded physicians seeing fewer than 10 patients per day as these physicians are providing types and patterns of care that are substantially different from those provided by other physicians (see Appendix 1, Table S1, for additional details). This exclusion can be modified when reproducing these methods for specific planning needs. We did not assess specialized practices such as low-risk obstetrics or palliative care, in which a physician might well bill fewer than 10 visits in what is nonetheless a full work day. It is possible that some of the physicians with high billing volumes were actually physicians supervising 1 or more nurse practitioners as those arrangements are not distinguishable in Alberta's data. However, very few physicians have such arrangements in Alberta. This method cannot distinguish with certainty whether a physician works half a day versus a full day. 


\section{Conclusion}

Our next step is to explore the full scope of practice activities being provided by PCPs and to compare physicians working PT and FT by activities. Given the trend toward newer graduates offering less direct patient care, working less but providing comprehensive, full-spectrum primary care may be the new norm. Policy-makers will need a clear picture of these nuances to plan accurately for health workforce supply in Alberta and across Canada.

\section{References}

1. Barker I, Steventon A, Deeny S. Continuity of care in general practice is associated with fewer ambulatory care sensitive hospital admissions: a crosssectional study of routinely collected, person-level data. Clin Med (Lond) 2017;17(Suppl 3):s16.

2. Cheng S-H, Chen C-C, Hou Y-F. A longitudinal examination of continuity of care and avoidable hospitalization: evidence from a universal coverage health care system. Arch Intern Med 2010;170:1671-7.

3. Menec VH, Sirski M, Attawar D, et al. Does continuity of care with a family physician reduce hospitalizations among older adults? $\mathcal{F}$ Health Serv Res Policy 2006;11:196-201.

4. Starfield B, Shi L, Macinko J. Contribution of primary care to health systems and health. Milbank Q 2005;83:457-502.

5. Tammes P, Morris RW, Brangan E, et al. Exploring the relationship between general practice characteristics and attendance at walk-in centres, minor injuries units and emergency departments in England 2009/10-2012/2013: a longitudinal study. BMC Health Serv Res 2017;17:546.

6. AHS physician workforce plan and forecast 2017-2018. Calgary: Alberta Health Services; 2018

7. Medical Services Commission (MSC) payment schedule. Victoria: British Columbia Ministry of Health.

8. Canadian Institute for Health Information. National Pbysician Database data release, 2017-2018: methodological notes. Ottawa: Canadian Institute for Health Information; 2019.

9. Frohlich N, Katz A, De Coster C, et al. Profiling primary care physician practice in Manitoba. Winnipeg: Manitoba Centre for Health Policy, Department of Community Health Services, University of Manitoba; 2006.

10. Globerman S, Barua B, Hasan S. The supply of physicians in Canada: projections and assessement. Vancouver: Fraser Institute; 2018.

11. Tepper J, Shultz S, Rothwell D, et al. Physician services in rural and northern Ontario. Toronto: ICES; 2006.

12. Physicians per 100,000 population by province/territory, 1986-2015. Ottawa: Canadian Medical Association; 2016.

13. Bourgeault I, Simkin S, Chamberland-Rowe C. Poor health workforce planning is costly, risky and inequitable. CMA7 2019;191:E1147-8.

14. Chan B. Supply of physicians' services in Ontario. Hosp Q 1999-2000;3:17.

15. Pong RW. Beyond counting heads: some methodological issues in measuring geographic distribution of physicians. Can 7 Rural Med 2002;7:12-20.

16. McDonald T, Seidel JE, Patel AB, et al. High-volume general practitioners in Alberta: a descriptive analysis. CMA7 Open 2018;6:E254-60.

17. Mainous AG III, Gill JM. The importance of continuity of care in the likelihood of future hospitalization: Is site of care equivalent to a primary clinician? Am 7 Public Health 1998;88:1539-41.

18. Cunningham CT, Cai P, Topps D, et al. Mining rich health data from Canadian physician claims: features and face validity. BMC Res Notes 2014;7:682.

19. Fees information for health professionals. Edmonton: Government of Alberta. Available: www.alberta.ca/fees-health-professionals.aspx (accessed 2020 Feb. 11).
20. Fee navigator. Edmonton: Alberta Medical Association. Available: www. albertadoctors.org/fee-navigator (accessed 2020 Feb. 11).

21. Murray M, Davies M, Boushon B. Panel size: How many patients can one doctor manage? Fam Pract Manag 2007;14:44-51.

22. Guide to panel identification for Alberta primary care. Edmonton: Alberta Medical Association; 2014.

23. Alberta Health Services annual report 2013-2014. Edmonton: Alberta Health Services; 2014.

24. Alberta Health. Official standard geographic areas. Edmonton: Alberta Health Services; updated 2018.

25. Jeon S-H, Hurley J. Physician resource planning in Canada: the need for a stronger behavioural foundation. Can Public Policy 2010;36:359-75.

26. Laurence CO, Karnon J. Improving the planning of the GP workforce in Australia: a simulation model incorporating work transitions, health need and service usage. Hum Resour Health 2016;14:13.

27. Fullerton M. Understanding and improving on 1 problem per visit. CMAf 2008; 179:623, 625 .

28. Schultz S, Glazier R, Graves E, et al. Payments to Ontario physicians from Ministry of Health and Long-Term Care sources: update 2005/06 to 2017/18. Toronto: ICES; 2019.

29. 2019 CMA Physician Workforce Survey results. Ottawa: Canadian Medical Association; 2019. Available: www.cma.ca/2019-cma-physician-workforce -survey-results (accessed 2020 Feb. 11).

30. Sarma S, Thind A, Chu M-K. Do new cohorts of family physicians work less compared to their older predecessors? The evidence from Canada. Soc Sci Med 2011;72:2049-58.

Affiliations: Department of Family Medicine (McDonald), and Clinical Research Unit (Lethebe), Cumming School of Medicine, University of Calgary, Calgary, Alta.; Department of Family Medicine (Green), University of Alberta, Edmonton, Alta.

Contributors: All authors participated in the conception of the study, data analysis and data interpretation. Terrence McDonald and Lee Green drafted the manuscript. All authors revised the manuscript critically for important intellectual content, gave final approval of the version to be published and agreed to be accountable for all aspects of the study.

Funding: Funding for this study was provided by the departments of family medicine of the University of Calgary and the University of Alberta and by a grant from the M.S.I. Foundation in Alberta.

Data sharing: Study data are maintained by the Clinical Research Unit of the Cumming School of Medicine at the University of Calgary. Requests for the study data should be directed to Alberta Health.

Disclaimer: This study is based in part on data provided by Alberta Health. The interpretation and conclusions contained herein are those of the researchers and do not necessarily represent the views of the Government of Alberta. Neither the Government of Alberta nor Alberta Health express any opinion in relation to this study.

Acknowledgements: The authors extend sincere thanks to Dr. Richard H. Glazier for his valuable input on the relevance and applicability of the service day methodology and to Dr. Diane Lorenzetti for her assistance with the literature review supporting this project.

Supplemental information: For reviewer comments and the original submission of this manuscript, please see www.cmajopen.ca/content/8/4/ E747/suppl/DC1. 